\title{
Using the media during Mental Health Week
}

\author{
Rob Kay, Barbara Martin, Doreen Kelly and Cameron Stark
}

\begin{abstract}
The mass media is an important source of public information on mental health iscues. A two-page insert in 11 local Ayrshire newspapers was purchased to coincide with the Mental Health Weeks in 1994 and 1995. Using a quota sampling technique, 379 adults were questioned on their views and recollection of the insert in 1994, and a further 365 in 1995. It had been seen by $27 \%$ of 1994 respondents, and by $22 \%$ in 1995 . Of these, $80 \%$ in each sample had read at least part. Local detalls were best remembered, and information on the nature of mental illness was regarded as the most helpful part of the insert. The newspaper articles provided a way of contacting a substantial proportion of the adult population of the area.
\end{abstract}

The closure of long-stay institutions has increased the public profile of mental illness. Enormous publicity has been generated by suicides, assaults and murders involving mentally ill people (Torrey, 1994). Increases in community treatment allow the public increased exposure to mental health issues, but their personal experience may be outweighed by adverse media coverage of uncommon events (Berlin \& Malin, 1991).

The Ayrshire and Arran Health Board area has had several discharge programmes, with accommodation being provided by voluntary organisations supported by the NHS, or by mainstream housing providers. In 1992-93 the discharge programme began to experience increased resistance from local communities. In one case, which attracted considerable local publicity, householders in an affluent area banded together to buy a house in order to block its acquisition for use with this client group.

In order to identify the barriers to a further shift to the community, the Health Board commissioned research from the University of Glasgow to review the attitudes of the public, and of professionals, service users and carers towards mental illness and the services and accommodation required for those affected. The work confirmed the preference of users for community options, but revealed widespread concerns among the general public, particularly when asked about the possibility of a group home being established near to themselves.

In order to tackle these problems, the Health Board has, together with organisations in the local authority and voluntary sectors, developed a mental health promotion strategy which includes recognition of the need to inform public opinion and to challenge preconceived ideas. A pilot project was carried out during Mental Health Week 1994, and repeated in 1995.

\section{Subjects, methods and findings}

A two-page insert was purchased in the local newspapers in all local government districts in the Ayrshire and Arran Health Board area, a total of 11 newspapers, during Mental Health Week 1994 and again in 1995. The two-page spread included nine separate items. System Three Scotland, a market research organisation, was commissioned to evaluate the impact of the programme by carrying out street interviews beginning one week after the publication of the article (this was delayed to two to three weeks after Mental Health Week in 1995). A quota sampling technique was used to obtain samples of 379 adults in 1994 and 365 in 1995, which reflected the age, sex, social class and geographical distribution of the Board area as a whole.

In 1994 the insert had been seen by $27 \%$ of respondents, with $80 \%$ of these having read at least some of it and $8 \%$ having read it all. The following percentages refer to the 90 people who had read some or all of the insert. Of these people, $68 \%$ stated that they had found it either very or quite interesting. The part of the insert which was most often recalled was a section on local events for Mental Health Week, with 23\% spontaneously citing it and a further $22 \%$ recalling it when prompted. The next most cited items dealt with local telephone numbers for mental health and support organisations, and that on "Things you didn't know about mental health". The least cited item discussed media coverage of mental health issues, with only $8 \%$ citing it even after prompting. The items rated as 
most useful were those discussing "what is a mental health problem?" and a selection of comments from service users, regarded as helpful by $85 \%$ and $80 \%$ respectively of those who had looked at it.

Results for 1995 were similar, although the street interviews were conducted two to three weeks after Mental Health Week, rather than the following week as had happened in 1994. An additional question on Mental Health Week itself was added in 1995. Of the 1995 sample, $42 \%$ stated that they had heard of Mental Health Week. More women than men reported knowing of the week (50\% compared with $34 \%$ ), and a larger proportion of people who knew someone with a mental health problem stated that they had heard of the week ( $46 \%$ compared with $39 \%$ of those who knew no one with a mental health problem). In order to elicit the degree of awareness of the week, those who had heard of the event were asked when it took place. Of these, $10 \%$ gave the exact dates, while a further $26 \%$ thought it had occurred in the previous two to three weeks. The remainder (64\%) were either unsure or gave an incorrect date.

In the 1995 group, $22 \%$ reported seeing the newspaper feature, with $81 \%$ of these having read at least some of it. Of those who read some of the feature, $78 \%$ found it either very or quite interesting, similar to the response in 1994. The two most useful, and best recalled, elements were "useful telephone numbers" and a list of local events. The events associated with the greatest reported interest were an art exhibition (35\% very or quite interested); an information and publicity shop display $(32 \%$ very or quite interested), and a Roadshow with West Sound, the local radio station $(27 \%$ very or quite interested). Open Days attracted the least interest, ${ }_{2}$ with less than $7 \%$ expressing interest in any of the local open days, such as those in hospitals, clinics, training or drop-in centres.

In 1994, information was collected on experience and attitudes, with $48 \%$ of respondents knowing someone with a mental health problem. Of those who knew anyone with a mental health problem, $15 \%$ agreed that "those with a mental illness should be kept in hospital", compared with $28 \%$ of those who did not know a sufferer. In addition, $37 \%$ of those aged over 55 years agreed with the statement compared with $14 \%$ of those aged 18-54 years. These differences were not statistically significant.

Results from 1995 were largely consistent with this. Of this sample, $84 \%$ agreed "mental health problems affect a lot of people directly". compared with $82 \%$ in 1994 . Eighty-three per cent agreed that the public "are often afraid of people with mental health problems", compared with $78 \%$ in 1994 . The statement that "those with a mental illness should be kept in hospital" found
$18 \%$ agreeing and $63 \%$ disagreeing, compared with $22 \%$ and $50 \%$ respectively in 1994 .

\section{Comment}

Public attitudes towards the resettlement of hospital patients in the community, and the increasing use of community treatments, are important in many ways. Adverse media publicity may cause calls for an increase in hospital provision and a decrease in community placements. Professionals often avoid the media because of worries about misquotation and oversimplification. Despite this, there are examples of successful use of media routes to communicate information about mental health issues (Barker et al, 1993; Wolff et al, 1996).

A media route was chosen for this project in an attempt to communicate with as many members of the public as possible, and because it is influential in shaping public attitudes towards mental illness (Lopez, 1991). The evaluation indicates that at least a fifth of the Health Board's adult population read at least some of the newspaper insert in each year, and that most of those who did look at it found it of interest. Local details were the best remembered, but items on the nature of mental illness were regarded as the most interesting. Traditional events, such as open days, aroused minimal public interest. Events such as art exhibitions, radio roadshows and displays in shops were far more acceptable.

The findings indicate that, at least in Ayrshire, Mental Health Week has to develop further if it is to have a greater impact on the public. Open days and other traditional forms of involvement appear to have little appeal. More innovative and accessible but time-consuming events, such as joint initiatives with local radio, are of wider interest.

Information will not, of itself, change attitudes. It does seem important, however, that the caring professions do not retreat from the media. Purchasing space in newspapers is one way to ensure that accurate details are transmitted. As a result of this work, the local Mental Health Media Group intends to place further articles in the press on mental health issues, and to seek to widen the type of event. Their content and structure will reflect the findings of the evaluation. Media campaigns, combined with appropriate evaluation and subsequent modification, may be one way of redressing the balance against sensationalist press coverage.

\section{Acknowledgements}

We are grateful to Louise Parker, Flona Moss, Lisa Ramsay and the members of the Mental Health Media Group who contributed to this work. 


\section{References}

Barker, C., Pistrang, N., Shapiro, D. A., et al (1993) You in mind: a preventive mental health television series. British Journal of Clinical Psychology. 32, 281-293.

BERLIN, F. S. \& MALIN, H. M. (1991) Media distortion of the public's perception of recidivism and psychiatric rehabilitation. American Journal of Psychiatry. 148, 1572-1576.

LOPEZ, L. R. (1991) Adolescents' attitudes towards mental illness and perceived sources of their attitudes: an examination of pilot data. Archives of Psychiatric Nursing, 5, 271-280.

TORREY, E. F. (1994) Violent behaviour by individuals with serious mental illness. Hospital and Community Psychiatry, 45, 653-662.
Wolff, G., Pathare, S., Craig, T., et al (1996) Public education for community care. A new approach. British Journal of Psychiatry, 168, 441-447.

Rob Kay, Business Manager, Priority Care Team, Ayrshire and Arran Health Board: Barbara Martin. Consultant Psychiatrist, Ayrshire and Arran Community Health Care NHS Trust, Doreen Kelly, Area Manager, Richmond Fellowship Scotland: and "Cameron Stark, Consultant in Public Health Medicine, Highland Health Board, Beechwood Park, Inverness IV2 3HG

*Correspondence

\title{
Gaskell Academic Series
}

\section{Interpersonal Factors in Origin and Course of Affective Disorders}

\author{
Edited by Ch. Mundt, M.J. Goldstein, K. Hahlweg and P. Fiedler \\ with the assistance of Hugh Freeman
}

This detailed overview of the latest research on affective disorders brings together authors of international background and repute. Both a theoretical and practical approach to the origin and course of affective disorders is presented, covering specific problems and settings. The principal areas covered are: personality factors, risk and course; social support; marital and family interaction; and intervention.

• £30.00 • 368pp. • Hardback • $1996 \bullet$ ISBN 0902241907

Available from good bookshops and from the Publications

Department, Royal College of Psychiatrists, 17 Belgrave Square, London SW1X 8PG (Tel. 0171-235 2351, extension 146)

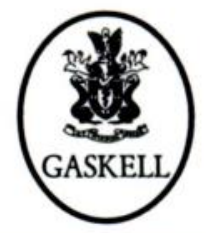

